\title{
Promoting responsible thinking and behaviour at Swiss universities
}

\begin{abstract}
Switzerland is in the top five most sustainable countries based on the Sustainable Competitiveness Rankings 2019; where Hungary has the $31^{\text {st }}$ place. In order to learn some practices from Switzerland, the approach of Swiss universities to sustainability is examined to provide Hungarian universities with practical examples.

The findings of the research lead to the conclusion that Swiss universities engage in several activities to raise awareness of sustainability and promote diversity and equality at their institutions. The research gives practical examples how Swiss universities integrate sustainability practices into the everyday life of their communities.
\end{abstract}

Keywords: Swiss universities, sustainability, responsible thinking and behaviour, megatrends

\section{Introduction}

Universities can reflect on social, economic, and environmental challenges. These challenges can be recognised if megatrends, such as New Ecology, Gender Shift and Culture of Knowledge are analysed. Megatrends, the great streams of change in the world, are part of our lives and play a crucial role in future developments. Identifying megatrends helps to describe the development processes that have the greatest impact on society in the medium and long term. Megatrends serve as orientations and show what might shape society in the future. Although the future cannot be predicted, megatrends may show the

1 PhD Student, University of Sopron, Alexandre Lámfalussy Faculty of Economics, István Széchenyi Doctoral School, Sopron, Hungary; e-mail: paulovics.agnes@phd.uni-sopron.hu DOI: http://dx.doi.org/10.31570/Prosp 2021_1 7 
direction in which the various improvements lead. Megatrends have an impact on the market, too. The market participants' constant challenge is to adapt to changes brought by development, to anticipate changes and to use them to the best advantage.

Universities should be particularly agile since these are the places, where future specialists, scholars and managers are trained. Therefore, they must constantly adapt to trends, develop new approaches and equip students with skills that make them successful in the future.

Sustainability, responsible thinking, and behaviour are some of the most important issues today. Not only because of the increased attention of Generation $\mathrm{Z}$ concerning these topics but because of such world issues as global warming, excessive waste production and social imbalance, too.

\section{The relevance of the topic}

Sustainability is one of the most crucial issues today. It can be seen as a challenge but at the same time, as an opportunity, too. Sustainability has become a guiding principle over the past few decades, and an increasing number of economic actors are focusing on sustainable behaviour in their practices, such as governments, companies, and public institutions like universities. Since sustainability is an essential term in today's world, it is of particular importance to investigate its application at universities.

\section{Problem statement and research objectives}

Switzerland is among the top-most sustainable countries, as it is shown by the Sustainable Competitiveness Rankings 2019. Based on the same rankings, Hungary owns the 31st place. Thus, it might be advantageous to study some aspects of Switzerland in relation to sustainability. This research paper examines the practices of Swiss universities to provide recommendations for other universities worldwide. The study aims to analyse how Swiss universities integrate sustainability aspects into the everyday life of their communities in order to promote responsible thinking and behaviour.

The objectives of the paper are:

- To clarify some essential terms and concepts applied in this research area. Thus, megatrends are analysed, the roles of universities are described, and the current state of research on the theory of promoting sustainability and encouraging responsible thinking and behaviour at universities worldwide is reviewed. 
- To examine the practices of some Swiss universities in presenting the implemented projects and concepts in the field of sustainability.

However, it is not the aim of this paper to show the full range of activities of Swiss universities and colleges in the field of sustainability. Rather, the research focuses on regional examples, behavioural patterns and the presentation of successful projects.

\section{Hypothesis}

The research hypothesis is that Swiss universities have a wide range of sustainability concepts and actively apply them. The wide range of concepts includes 10 approaches for each university on average. Concepts consist of projects starting from small ideas and their realizations, like the selective collection of waste, all the way to overall strategies that stretch over the years and the boundaries of the universities.

The data are collected, analysed, and researched in order to provide a compiled list of recommended concepts that might be applied by other schools, high schools, and universities all over the world.

\section{Research question}

The research examines the following research question:

How do Swiss universities integrate sustainability practices into the everyday life of their communities in order to promote responsible thinking and behaviour?

\section{Trends}

The term "trend" was first used for the course of stock market prices in the 19th century. Nowadays, it is widely applied and often misused. A large part of the society understands this notion as a short-term fashion trend, but there is much more behind this word. There is not only the term "trend", but there are different types of versions, which are widespread and different (Trends - Grundlagenwissen, n. d.).

The following part explains the details of each orientation:

\section{- Metatrends}

Metatrends are the biggest and longest lasting trends. They combine several megatrends into one and are the basis of all trends and developments. They are com- 
prehensive and represent the basic rules of nature and the laws of evolution with eternal character (Horx 2015).

\section{- Megatrends}

Megatrends represent social, economic, political, ecological or technological changes (Hajkowicz 2015) that influence the activities, processes and perceptions of individuals, companies, societies and governments for decades. Megatrends serve as a tense change that is not under the individuals' direct influence and control. However, all human beings have the power to alter their destiny. People have to learn to understand the flows and predict probable future scenarios, which is crucial to be able to maintain the power of decisions for the future. (Hajkowicz 2015).

The term was complemented in 2005 by Gänssmantel, Geburtig, and Schau. The researchers added that megatrends are not subject to cycles, instead they can be represented as wave models with very slow rates of changes (Gänssmantel et al. 2005).

Megatrends have a lifespan of 50-60 years. They have an impact on all possible areas of life and are global phenomena. Although they do not occur at the same time everywhere, they have a global character. Megatrends change the world slowly and fundamentally (Megatrends, n. d.).

- Socio-cultural trends

Socio-cultural trends have a maximum lifespan of 10 years, so they are mediumterm trends. They are based on the social and technical changes in the life of mankind.

- Consumption and zeitgeist trends

Consumption and zeitgeist trends are among the short- and medium-term trends that exist for a maximum of 5-8 years. They are reflected in the change of products and the consumer world.

- Product and fashion trends

Product and fashion trends are the shortest-term trends, and they mostly last only for one season. They are superficial and have an impact solely on the products (Trends - Grundlagenwissen, n. d.). 
As it is presented in the previous paragraphs, several types of trends exist. Some are very ephemeral; others influence the market in the medium or even long term. Depending on the business sector, market participants should follow and react to the various types of trends. Universities are important players in the market; therefore, they should adjust their offers towards the future needs in order to attract students even in the long term and to conduct research that is relevant to their stakeholders. In addition, universities must adapt their behaviour to these trends to maintain their validity.

\section{Megatrends}

As this study focuses on megatrends and their impact on the life of universities, a more detailed explanation of the term is provided in this section.

Megatrends are those trends that affect the life of every individual in a variety of ways. Society faces a fast-changing and hectic time, which is affected by countless developments and trends. These transformations exert pressure on the everyday life, the work, and the behaviour of people.

Megatrends consist of a multitude of individual but closely interlinked streams that interact with each other. They reshape and change the way people live and thus, create new needs (Lux 2012).

ZukunftsInstitut, which provides strategic knowledge for the economy of tomorrow, is one of the most important think tanks for trend \& future research. Describing all megatrends goes beyond the scope of this research; therefore, the focus is set on those that are particularly important for universities.

Among the megatrends, those that make an effect on universities are the followings:

- New Ecology: It realigns the values of society, culture and politics and leads to a new way of entrepreneurial thinking and acting.

- New Work: Since machines might take over many tasks from humans, the world of work is transformed, too. In the long term, it comes down to an optimal harmony of living and working.

- Gender Shift: Gender has never had such a low impact on the roles taken on in society as nowadays. Stereotypes are broken down leading to radical changes.

- Individualisation: It shapes the current cultural trends. This megatrend widely spreads especially, in the West. The term stands in the broader sense for the freedom of choice. 
- Culture of knowledge: The megatrend knowledge culture indicates that new forms of innovation and joint research emerge. Knowledge becomes common property and consequently, loses its elitist characteristic.

- Connectivity: Networking leads to social changes and opens a new chapter in the evolution of society. Connectivity creates new lifestyles and patterns of behaviour.

- Health: Health and satisfaction grow together over the years. Health serves as a central objective in life and becomes deeply ingrained in people's consciousness.

- Mobility: An increasing variety of mobility forms emerge.

(Megatrends, n. d.)

\section{Sustainability}

The term "sustainability" is primarily associated with environmentally conscious actions, the saving of resources and renewable raw materials (Nuremberg Institute for Market Decisions, 2016).

However, sustainability is a more complex term, which includes economic, ecological, and social perspectives. In case of economic sustainability, importance is attached to the ensuring of a company's sustainable production in the future besides, its economic success. Ecological sustainability includes the attempt to handle resources in a way that they remain available to the new generations to the same extent as now. Social sustainability means that companies treat their stakeholders in a way that they remain constantly willing to cooperate (Clausen 2009).

Since the definition of sustainability is not adequately defined, for companies, it leaves ample room for interpretation. As a result, market participants are free to define their own terms of sustainability. Thus, the same term does not meet the same requirements. However, the aim of the term's use is to distinguish sustainable from less sustainable developments (Grunwald 2004).

Sustainability is a prerequisite for ethical action, which can be achieved by improving economic, social and environmental compatibility, as well (Zerres-Zerres 2011). Today the aim of ethics is to show consumers how to act sustainably. Consumers no longer want to consume thoughtlessly, but consciously wish to control their consumption. Instead of a throw-away society, people want to use the system in a way that makes it available in its present form for future generations, too (Neo-Ökologie - Der wichtigste Megatrend unserer Zeit, 2019). 


\section{Universities}

\section{Historical review}

Universities that operate as the academic institutions of higher education have existed for many years. Bologna is known as the oldest university. It was already founded by 1088, and since that time, it has never been out of operation (Tucker 2020). Until the 18th century, the schools had to be licensed by the Pope and additionally, by the king or emperor of the country to obtain the permission to award academic degrees (von Schulte 1881). The Faculty of Medicine of Bologna was recognized by the Pope in 1219, and it has been officially a university ever since (Bonomini et al. 1994).

The University of Bologna's foundation was followed by the University of Oxford. Oxford University was established in 1096, and its alumni list 28 UK Prime Ministers, 20 Archbishops of Canterbury, 12 saints, 27 Nobel laureates and 50 Nobel Prize winners (Tucker 2020).

The third oldest university, the University of Salamanca, was the institution where Christopher Columbus pleaded for royal support for his Indie expedition in the late 15th century (Tucker 2020). Besides European universities, there started to be more and more learning centres all around the world. For example, El Azhar, with records from 975, is known as the oldest educational institution of the East (Penfield 1896).

These historical events, their attendants and heritage show the importance of universities for society. Universities are of central relevance to the world even today since knowledge is considered to be a crucial resource of the economy of the 21st century (Ortiz 2013).

\section{The role and the relevance of universities}

Universities fulfil a wide range of roles:

- Generating knowledge

- Providing qualifications for skilled workers

- Establishing know-how transfer between companies and universities

- Creating regional knowledge infrastructures

- Developing technical innovations, in the form of patents or spin-offs

- Participating in political and civil decision-making processes

- Providing intellectual, cultural, artistic, or moral impulses 
- Increasing the autonomous demand by the regional expenditures of the universities for material and services (Glückler-Panitz-Wuttke 2015).

The above-mentioned aspects are all important for universities. However, as based on the objective of the research, a deeper focus is placed on the factors that can be related to students and the development of their responsible thinking and behaviour. Universities are the sources of knowledge and technology; therefore, these institutions are important for regional cooperation partners (Ortiz 2013). Consequently, universities are of great importance for a region because they facilitate the transfer of knowledge (Hagen 2006). By training skilled workers, the youngsters with fresh knowledge enter the industrial field and companies profit from this know-how transfer. Therefore, the kind of skills and information that are taught to the students at universities are of central importance. Since many companies today focus on sustainability, issues and topics related to this field should be discussed at schools and universities, as well.

\section{Sustainability, and promoting responsible thinking and behaviour at universities}

During the academic years, students acquire skills in several fields. Universities provide opportunities to gain new knowledge, to build relationships and to take part in freetime activities. Institutions of higher education have a responsibility to contribute to the technical knowledge as well as the moral development of their students. Due to the environmental changes and the new requirements in the area of sustainable thinking, the concepts of academic disciplines need to be examined and the literature reviewed.

Universities approach the challenges caused by sustainability in various ways, but there are some essential obligations that all of them should take on:

- Commitment to sustainability in their mission statement

- Incorporation of sustainability concepts into all academic disciplines

- Teaching students to reflect on the ecological and social roles of the university

- Making knowledge about sustainability a criteria for hiring and promotion

- Putting effort into reducing its ecological footprint

- Representing sustainability in campus life

- Forming partnerships that support sustainability both locally and globally (Leal Filho 2000). 
The universities that focus on sustainable development strengthen the reflective potential of 21 st century societies. Behind all sustainable developments lies a comprehensive process of change that requires social actors. In order to successfully establish a sustainability orientation, research and teaching at universities must consciously focus on a number of central societal challenges and involve societal actors from the outset in the processing of scientific questions. Universities must ensure that they have sufficient capacities for research and teaching in the social and cultural sciences. This would also ensure that they are in a position to address major societal challenges at the starting point of their research and teaching and to shape change processes with the involvement of societal actors. By this attitude, educational institutions become transformative universities, which actively accompany the social change processes with actors (Schneidewind 2009, 2014).

Schneidewind (2014) names five prerequisites for anchoring sustainability in university environment.

- Researchers and teachers should be open to research questions from outside and be prepared to put up with the effort to communicate and cooperate with disciplines and practitioners who in some cases, are not so related to their fields.

- Students must develop the independence to ask their own questions and demand answers to these questions from their universities.

- University administrations and departments must be prepared to rethink faculty and university structures to build up their agility to deal with social challenges.

- The university's network of cooperation partners must be anchored in society far beyond the corporate contacts, and the university must be positioned as a cooperation partner on an eye-level within this network.

- Transdisciplinary research and teaching must become an important component in the education of young academics in order to meet future demands.

\section{Methodology}

The concepts of megatrends, university and responsible thinking and behaviour at universities have already been presented to provide a common understanding of these ideas by analysing secondary sources.

In the primary research part of the study, documents from Swiss universities that originate from the websites of the educational institutions are examined. The research aims to uncover and explain unique projects, from small initiatives to large strategic 
projects. In addition to presenting some selected projects, patterns are sought that indicate which projects are implemented at several institutions.

\section{Findings}

The research focuses on three Swiss universities: ETH - Swiss Federal Institute of Technology, EPFL - Ecole Polytechnique Fédérale de Lausanne and UZH - University of Zurich. These institutions are all ranked in the world's top 100 based on the QS World University Rankings 2019.

\section{Hypothesis review}

The sources of the research originate from the "2017/2018 Sustainability Report" for ETH, from "EPFL Sustainable Campus - 2018 Highlights" for EPFL and from "2018 Sustainability Report" for the University of Zurich (for further information see References).

Table 1 shows the distribution of the universities' sustainability projects. For the research, the last available publications are used; therefore, there are differences in the years. The evaluation is made based on the available documents. Thus, various projects that are not included in the calculation due to the lack of sources may exist.

The three surveyed universities have an average of 26.3 projects per educational institution, that was calculated with the following formula:

$$
\overline{\boldsymbol{x}}=\frac{\sum_{i=1}^{n} x i}{n}=\frac{30+21+28}{3}=26.3
$$

The examined hypothesis of the research is that "Swiss universities have a wide range of sustainability concepts and actively apply them". The term "wide range" means an average of 10 concepts for each university. Moreover, all projects are considered starting from small ideas and realisations, such as the selective collection of waste to comprehensive strategies that stretch over years and the borders of the institutions.

As $26.3>10$, the hypothesis cannot be rejected as the data do not contradict the statement. 
Table 1: Sustainability initiatives at Swiss Universities

\begin{tabular}{c|c|c|c}
\hline University & Year & Initiatives & Sources \\
\hline $\begin{array}{c}\text { ETH - } \\
\text { Swiss Federal Institute of Technology }\end{array}$ & $\begin{array}{c}\text { 2017-2018 } \\
\text { school year }\end{array}$ & 30 & (Kassab et al. 2019) \\
\hline $\begin{array}{c}\text { EPFL - } \\
\text { Ecole Polytechnique Fédérale de } \\
\text { Lausanne }\end{array}$ & 2019 & 21 & (EPFL, n. d.) \\
\hline $\begin{array}{c}\text { UZH - } \\
\text { University of Zurich }\end{array}$ & 2018 & 28 & $\begin{array}{c}\text { (Bieser-Warland-Hilty } \\
\text { 2019) }\end{array}$ \\
\hline
\end{tabular}

Source: own illustration

\section{Sustainability projects overview}

The researched projects of the universities are classified into six areas: Education, Research \& Awards, Community, Energy, Waste and Mobility. The distribution of the projects among the different areas reveals that most of the projects take place in the field of Community. In total, there are 24 external and five internal realised projects. 11 projects are implemented in the areas of Research \& Awards and Waste followed by Mobility solutions with nine completed projects. There were nine-nine executed initiatives in each of the areas of Energy and Education.

Figure 1: Realised projects per segment

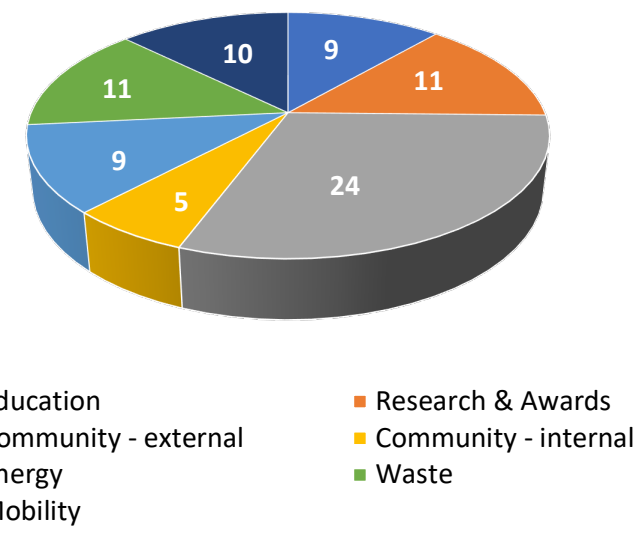




\section{The description of the projects per area}

In this section, one or more projects from each segment are presented. The selection of the project is based on the fact whether the project is realized by several institutions. Projects with recurring realisations are presented, even if their forms are different.

The projects in the area of Education include a wide range of offers. On the one hand, students are invited to new learning environments, where collaborative work is encouraged. On the other hand, new courses are offered that educate students on sustainable development. Many projects are realized in the field of digitization of education. For example, further education is offered as MOOC courses, lectures are recorded and then made available to students as podcasts or teleteaching is introduced to some departments. In their free time, students are offered health sessions, which focus on self-care, too.

In the field of Research and Awards, universities focus on solving global health problems and conflicts between ethnic minorities and central state governments. Furthermore, universities dedicate student projects to sustainability, too. Additionally, several professors are awarded for their findings in the field of conflict research, their contribution to the welfare of humanity as well as awards for students dedicating their projects to the economic, social, and environmental dimensions of sustainability.

Community engagement was already mentioned 11 years ago as a solution for increasing sustainability awareness at universities. It leads to knowledge exchange, the discussion of ideas, and the project participants feel involved (Hendricks-Cope-Harris 2009).

There are two types of community-based projects: internal and external. In the form of internal projects, universities invite students to get involved and share their ideas on sustainable solutions, which might be realized in cooperation with and under the support of the university. Educational institutions organize sustainability weeks as well as events where students may deepen their knowledge and act in the area of sustainability. To promote health and emphasize the importance of healthy nutrition, universities host vegetable markets, where local fruit and vegetables are sold to the students. Additionally, students and staff might create vegetable patches together, or build an allotment garden at the campus.

The list of external community building is the longest of all activities. It covers such areas of communication in which universities try to increase the visibility of women in research to motivate young women to pursue scientific careers. This area stretches over to the clear communication of their Code of Conduct with a zero-tolerance policy concerning discrimination, sexual harassment, bullying, or threats and violence. 
Educational institutions focus on the networking with any kind of market participants. Universities encourage citizens to participate in all phases of research projects to promote knowledge transfer. The project "Treffpunkt Science City" of ETH Zurich offers free education for anyone in the form of lectures, demos, lab visits and talk shows. Swiss universities organize Industry Days, where they demonstrate their research activities and offer a platform for industry representatives to engage with the university's leading researchers. ETH Zurich is represented at the World Economic Forum to enhance their contacts with global partners. Additionally, to build and strengthen their relationships with young generations, a special edition of Globi - one of the bestknown comic books in Switzerland - was first published in 2017 in collaboration with ETH and is up for sale still today.

Cybathlon organized by ETH is a competition for people with disabilities, where teams from all over the world compete against each other.

The goal of all educational institutions is to reduce their ecological footprint and to save energy. To achieve their aims, universities invest in MINERGIE ${ }^{\circledast}$ certificates and renovate their buildings. ETH is committed to reducing greenhouse gas emission by $10 \%$ over the next three years with aligning their gastronomy offers at the campus.

Furthermore, universities focus on reducing food waste and introducing reusable and washable dishes. As part of the waste management, recycling is introduced at universities, and boxes are available for biogenic waste, as well. To ensure the safety of their students and employees, the institutions offer special training on the disposal practices of hazardous waste.

The goal of Swiss universities is to reduce their paper usage and increase the usage of recycled paper. The University of Zurich has already launched a pilot project for paperless final exams.

The last research area is Mobility. Universities generate a high amount of $\mathrm{CO}_{2}$ emission due to the travelling of students and co-workers. Educational institutions attempt to solve this problem while maintaining excellence in science. The sustainable ways are promoted not just for business trips but for commuting, as well. Educational institutions encourage their stakeholders to use public transport on the one hand, by providing special conditions and discounts, on the other hand, by supporting car-sharing subscriptions. Additionally, bike parking places and e-bikes for rent are offered, as well.

As indicated by the high number of sustainability projects, these three universities have very diverse and future-oriented sustainability projects. Their focus lies not on one area rather the universities are engaged in projects from all six areas. 
If the relationship between the projects and the megatrends are analysed, it can be recognized that each of the megatrends is represented in one or the other initiatives. This demonstrates that universities are future-oriented and keep up with the emerging trends. This attitude enables them to offer their students the best possible education and to support them in their personal development, too.

\section{Conclusion}

The research focuses on the question: "How do Swiss universities integrate sustainability practices into the everyday life of their communities in order to promote responsible thinking and behaviour?" The findings of the primary research - conducted based on the reports of universities - lead to the conclusion that Swiss universities engage in several actions to raise awareness of sustainability and to promote diversity and equality at their institutions. Their actions rest on six pillars, i. e., in the areas of Education, Research \& Awards, Community, Energy, Waste, and Mobility. The educational institutions are mostly engaged in community building, especially by promoting knowledge exchange and transfer, by involving stakeholders from different areas, and by getting the community to participate.

For further research, the sustainability concepts of the Hungarian universities are suggested to be examined and compared with the approaches of Swiss universities. This might provide an insight into which aspects of the Hungarian education system may be enhanced. Subsequently, an execution plan might be created to define the stages of the implementation process.

\section{References}

Bieser, J. C. T. - Warland, L. - Hilty, L. M. (2019). 2018 Nachhaltigkeitsbericht [2018 Sustainability report]. Retrieved from https://www.sustainability.uzh.ch/dam/ jcr:a90b317e-37f9-4d9d-9d4d-d32d4e2e6c5c/NBUZH DE.pdf

Bonomini, V. - Campieri, C. - Scolari, M. - Zuccoli, M. (1994). The age-old spirit of nephrology from the oldest university in the world. American Journal of Nephrology, 14(4-6), 361-364. Retrieved from https://doi.org/10.1159/000168748

Clausen, A. (2009). Grundwissen Unternehmensethik: Ein Arbeitsbuch [Basic knowledge business ethics: A workbook]. Tübingen, Germany: UTB GmbH. 
EPFL (n. d.). EPFL sustainable campus - 2018 highlights. Retrieved from https://www. epfl.ch/about/sustainability/wp-content/uploads/2019/04/EPFL Rapport Campus durable EN 2019 2.pdf

Gänssmantel, J. - Geburtig, G. - Schau, A. (2005). Sanierung und Facility Management: Nachhaltiges Bauinstandhalten und Bauinstandsetzen [Renovation and facility management: Sustainable building maintenance and repairs]. Wiesbaden, Germany: Vieweg+Teubner Verlag.

Glückler, J. - Panitz, R. - Wuttke, C. (2015). Die wirtschaftliche Wirkung der Universitäten im Land Baden-Württemberg [The economic impact of universities in Baden-Württemberg]. Raumforschung und Raumordnung, 73(5), 327-342. Retrieved from https://doi.org/10.1007/s13147-015-0360-9

Grunwald, A. (2004). Nachhaltigkeit begreifen: Zwischen Leitbild und Trugbild [Understanding sustainability: Between mission statement and illusion]. GAIA - Ecological Perspectives for Science and Society, 13(1), 1-3. Retrieved from https://doi. org/10.14512/gaia.13.1.1

Hagen, M. (2006). Wissenstransfer aus Universitäten als Impulsfaktor regionaler Entwicklung - Ein institutionenökonomischer Ansatz am Beispiel der Universität Bayreuth [Knowledge transfer from universities as an impulse factor for regional development - An institutional economic approach using the example of the University of Bayreuth]. Arbeitsmaterialien zur Raumordnung und Raumplanung, 246, 1-358.

Hajkowicz, S. (2015). Global Megatrends. Clayton South, Australia: Csiro Publishing. Retrieved from https://doi.org/10.1071/9781486301416

Hendricks, J. - Cope, V. - Harris, M. (2009). Pragmatic truths - when ritual meets the reality of community. In Leal Filho, W. (ed.): Sustainability at Universities - Opportunities, challenges, and trends, 36-49. Frankfurt am Main, Germany: Peter Lang $\mathrm{GmbH}$.

Horx, M. (2015). Metatrends: Wie Komplexität entsteht [Metatrends: How complexity arises]. ZukunftsInstitut. Retrieved from https://www.Zukunftsinstitut.de/artikel/ future-forecast/metatrends-wie-komplexitaet-entsteht/

Kassab, O. - Bratrich, C. - Guggenheim, C. - Knutti, R. (2019). Sustainability report -2017/2018. Retrieved from https:/ethz.ch/content/dam/ethz/main/eth-zurich/ nachhaltigkeit/Berichte/Nachhaltigkeitsbericht/ETHzurich Sustainability Report 20172018 web.pdf

Leal Filho, W. (2000). Sustainability and university life. International Journal of Sustainability in Higher Education, 1(1). Retrieved from_https://doi.org/10.1108/ ijshe.2000.24901aae.005 
Lux, W. (2012). Innovationen im Handel: Verpassen wir die Megatrends der Zukunft? [Innovations in retail: Do we miss the megatrends of the future?]. Ingolstadt, Germany: Springer Verlag Berlin Heidelberg. Retrieved from https://doi.org/10.1007/978-3$\underline{642-28121-1}$

Megatrends (n. d.). ZukunftsInstitut. Retrieved from https://www.zukunftsinstitut.de/ dossier/megatrends/

Neo-Ökologie - Der wichtigste Megatrend unserer Zeit [Neo-ecology - The most important megatrend of our time]. (2019). ZukunftsInstitut. Retrieved from https:// onlineshop.zukunftsinstitut.de/shop/neo-oekologie-der-wichtigste-megatrend-unserer-zeit/?gclid=Cj0KCQjwlvT8BRDeARIsAACRFiWSGzIrrBRAgboUz3El4Cnv mSXm5kUiyWGkQE8EqeNjzDty3Ys7HhUaAvmlEALw wcB

Nuremberg Institute for Market Decisions (2016). Nachhaltigkeit: Mehr als eine Worthülse [Sustainability: More than just an empty phrase]. Nuremberg Institute for Market Decisions. Retrieved from https://www.nim.org/compact/fokusthemen/ nachhaltigkeit-mehr-als-eine-worthuelse

Ortiz, A. (2013). Kooperation zwischen Unternehmen und Universitäten: Eine Managementperspektive zu regionalen Innovationssystemen [Cooperation between enterprises and universities: a management perspective on regional innovation systems]. Wiesbaden, Germany: Springer Gabler. Retrieved from https://doi.org/10.1007/9783-8349-3644-8

Penfield, F. E. (1896). The world's oldest university. The Idler, 102, 193-196.

Schneidewind, U. (2009). Nachhaltige Wissenschaft. Plädoyer für einen Klimawandel im deutschen Wissenschafts-und Hochschulsystem [Sustainable science. Plea for climate change in the German science and higher education system]. Marburg, Germany: Metropolis.

Schneidewind, U. (2014). Von der nachhaltigen zur transformativen Hochschule. Perspektiven einer "True University Sustainability” [From the sustainable to the transformative university. Perspectives of a "True University Sustainability"]. Uwf UmweltWirtschaftsForum, 22(4), 221-225. Retrieved from https://doi.org/10.1007/ s00550-014-0314-7

Trends - Grundlagenwissen [Trends - Basic knowledge]. (n. d.). ZukunftsInstitut. Retrieved from https://www.zukunftsinstitut.de/artikel/trends-grundlagenwissen/

Tucker, L. (2020). 10 of the oldest universities in the world. Top Universities. Retrieved from https://www.topuniversities.com/blog/10-oldest-universities-world 
von Schulte, J. F. (1881). Gedanken über Aufgabe und Reform des juristischen Studiums [Thoughts on the task and reform of legal studies]. Bonn, Germany: Max Cohen \& Sohn.

Zerres, C. - Zerres, M. (2011). Einführung in die Marketing-Methodik: MarketingMethodik I [Introduction to marketing methodology: Marketing methodology I]. Retrieved from http://rybarecords.de/eBooks/Marketing/einfuhrung-in-die-marketing-methodik.pdf 